\title{
Digital Divide, Digital Inclusion and Inclusive Education
}

\author{
Ileana Hamburg \\ IAT, Westfälische Hochschule GE \\ Germany \\ Gabriela Lütgen \\ IAT, Westfälische Hochschule GE \\ Germany
}

\begin{abstract}
Digital divide refers to the gap of unequal accessibility and experience for access and use of modern information and communication technologies; digital inclusion has a focus on a practical, policy-driven approach in this context that addresses the needs of communities as a whole. Inclusive education is a process of strengthening the capacity of education systems to reach out all learners being welcomed in regular classes and to support them to learn, contribute and participate in all aspects of the life in schools and training institutions. Inclusive education is in many European countries at the beginning, even though it has numerous benefits and supports digital inclusion. This chapter presents some aspects of supporting inclusive education through digital technologies, the impact of digital divide and digital inclusion on inclusive education and how could digital platforms support digital inclusion. Some example of European projects with own participation of authors are presented where inclusive educational methodologies and technologies have been developed to minimize the negative impact of digital divide on people with disabilities and support inclusive education and training.
\end{abstract}

Keywords: Digital divide, digital inclusion, inclusive education, assistive technologies, digital platforms

\section{INTRODUCTION}

Inclusive education is a process of strengthening the capacity of education systems to reach out to all learners (European Commission, 2014) that means that all students attend and are welcomed in regular classes and are supported to learn, contribute and participate in all aspects of the life in schools and training institutions.

Inclusive education requires to develop schools and training institutions, classrooms, programs and activities so that all students learn and participate together. The benefits of inclusive education are numerous and digital technologies can support inclusive education. But despite the exponential growth of technology in the digital era, there exists an economic, educational, and social schism between those who have easy and unregulated access to the internet and those who do not.

Digital divide refers to the gap of such unequal accessibility and experience referring access and use of modern information and communication technologies.

The term digital inclusion is still quite new and address issues of opportunity, access, knowledge, and skills at the level of digitalization policy. Some of the questions which will be addressed in this chapter are: 
- Support digital technologies inclusive education?

- Which is the impact of digital divide and digital inclusion on inclusive education?

- How will be the digital platforms in order to support digital inclusion?

The authors present some examples of European projects with own participation where inclusive educational methodologies and technologies have been developed to minimize the negative impact of digital divide and support inclusive education and training.

\section{DIGITAL DIVIDE AND DIGITAL INCLUSION}

Ballestero (2002) identifies four elements related to the digital divide:

- Availability of hardware to connect to the Internet

- Possibility of access to the Internet

- Knowledge to access and navigate the Internet

- Ability to transform online information into knowledge benefiting the user

Some authors (i.e. Ballestero, 2002) document the significant benefits that digital technologies provide to those who have and know how to use them, benefits to which those who do not have or know how to use them are excluded. To address this situation, a concept has been proposed is called digital inclusion which refers to a form of societal integration necessary for community growth beyond quantitative and technological aspects of digital divide.

Digital inclusion has been defined as the set of public policies related to the installation, administration, expansion, creation and development of content on wired and wireless public digital networks in individual countries, regions and communities. It includes privacy and security guarantees exercised fairly for all and encompasses training and incentives to develop new tools (Robinson, 2005).

Whereas discussion around the digital divide tends to focus on the access available to individuals (Hamburg and Lütgen, 2018), digital inclusion a focus on a practical, policy-driven approach that addresses the needs of communities as a whole (https://digitalinclusion.umd.edu/content/what-digital-inclusion).

Following issues of digital inclusion show the goal of creating digitally inclusive communities (https://digitalinclusion.umd.edu/content/what-digital-inclusion):

- Access: Availability, affordability, design for inclusion, and public access.

- Adoption: Relevance, digital literacy, and consumer safety.

- Application: Economic and workforce development, education, health care, public safety and emergency services, civic engagement, and social connections.

The World Health Organization WHO (2011) appreciatse that, approximately 15\% of the world's population lives with some form of disability, 2-4\% have significant difficulties by daily activities. A significant number of people are unable to access technology because it wasn't designed with everyone in mind. In USA 54\% of households with a disability use the Internet, compared to $81 \%$ of households with no disability.

Many authors mention that digital technologies have the potential to enhance people's power to act and promote equal citizen participation. These elements are particularly important for people living with disability because for most people, technology makes things easier but for people with disabilities, technology makes things possible. Digital technologies enable persons with disabilities to access inclusive education, skills development, and employment (Broadband Commission for Digital Development et al. 2013). First because Internet and other 
digital technologies are becoming common and popular channels for the delivery and implementation of governance, welfare, socioeconomic development, and human rights programming (Samant, Matter, and Harniss 2012). They enable direct interactions between producers and markets globally, new methods of delivering personalized public and social services quickly, different channels for income generation, and innovations in asset accumulation and access to finance (Omole 2013). Multiple delivery channels are being used for communication and service delivery including email, text messaging, voice communications, and video. People with physical disabilities could be helped by the presence of assistive technology to bridge the gap. But i.e. the lack of access to personal devices and the Internet is prevalent among those with cognitive, hearing and visual impairments.

Additionally, persons with disabilities in low and middle-income countries face significant challenges in acquiring special devices such as the cost and availability of standalone, specialized equipment (WHO and World Bank 2011). This can be a barrier to their use in promoting the independent living, education and employment (Broadband Commission for Digital Development et al. 2013).

Digital divide focuses on access to ICT (or lack of), digital inclusion addresse needs of individuals and communities as a whole and can be viewed as a framework for addressing the readiness of communities to fully accept and prepare for the digital age.

Digital inclusion can be promoted in education. Schools and libraries already provide free access to digital technologies including hardware, software and high-speed Internet. These organizations can also provide digital content to their respective communities, as well as improve digital literacy skills through practical training programs and workshops. Digital inclusion initiatives such as health and employment services, can also improve digital literacy and access to technology. This includes making essential services, such as education, employment, commerce, and government accessible through digital technologies.

The United Nations has suggested a rethinking of education systems, considering the advantages of digital technologies and their repercussions on human development (United Nations, 2001). Within this task, the levels of digital inclusion in education must be determined as well as indicators developed for that purpose at the global or regional level.

A set of technology indicators were published in 2005 being developed by members of the Partnership on Measuring digital technologies for Development (2010), who have reviewed and expanded the indicators in all areas.

According to a study by the United Nations Educational, Scientific and Cultural Organization (Unesco, 2013), targets directly related to education are:

- Proportion of technology qualified teachers in schools and Proportion of teachers trained to teach subjects using digital technologies.

- Proportion of schools with computer-assisted instruction.

- Proportion of schools with Internet-assisted instruction.

Indicators related to education can be:

- Students-to-computer ratio by educational level.

- Percentage of primary and secondary schoolteachers trained to teach one or several subjects using digital resources, by educational level.

- Percentage of grades using assisted learning, by subject: mathematics, sciences, basic computer skills (computer science), languages, art.

- Proportion of public educational content that is digitalized. 
Concepts like digital inclusion and digital tools bring opportunities for an interactive distance education and for more personalized learning, adapted to the needs of every student and so support the implementation of inclusive education.

\section{DIGITAL TECHNOLOGIES AND INCLUSIVE EDUCATION}

Inclusive education "as an overall principle, should guide all education policies and practices, starting from the fact that education is a basic human right and the foundation for a more just and equal society" (European Agency, 2014). Inclusive education is in many European countries at the beginning. Germany has made little progress in moving special-needs children from special to regular schools. In fact, the German labor market has a better track record with handicapped adults (https://www.handelsblatt.com/today/politics/un-pact-10-years-ongermany-still-lags-in-inclusive-education/23580564.html?ticket=ST-1592536e9Wh6KVOHB6KbhpFRay0-ap1).

While in many parts of the world handicapped children go to regular schools with other children, the practice only became mainstream in Germany's schools 10 years ago when the country ratified the UN Convention on the Rights of Persons with Disabilities. Although the new inclusionary approach means excluding no one, in Germany it still doesn't always work, a recent Bertelsmann Foundation study shows.

According to the study, 4.9 percent of all students in Germany attended a special school during the 2008 to 2009 school year; eight years later, the figure was still 4.3 percent - only 40,000 fewer children. Too many children with special needs, including those who have social or emotional problems, are still taught in separate schools, too few in mainstream schools. Sure, the special educational schools are one way for development of learners with special needs but almost three quarters of all students at special schools do not achieve a secondary school qualification (UNESCO, 2008).

The International Classification of Functioning, Disability and Health (ICF) developed by the World Health Organization (WHO), uses the term 'participation' rather than 'inclusion' (ICF, 2001; Simeonsson et al., 2003), and acknowledges the many barriers faced by children with disabilities in their educational experience.

Inclusive education concept has been developed by the need of equality in approach for the education of the 'disabled' by giving them the possibility to use their differential abilities, proving themselves capable enough to learn and perform together with non-disabled colleagues (Hamburg and Bucksch, 2017). Efficient inclusive education implies placing students in general education classrooms regarding different criteria; (Becta, 2007; Porter et al, 2011). It involves acceptance of individual needs and differences, requires educators to adapt their teaching practices to individual needs (Donally, 2011).

Inclusive education means that all learners, with or without disabilities, could learn together through access to common pre-school provisions, schools and community educational setting with an appropriate network of support services. Inclusive education can be implemented only in a flexible education system considering considers the needs of diverse learners and adapts itself to meet these needs; it ensures that all stakeholders accept diversity and see it also as a challenge not only as a problem.

Some benefits of inclusive education are:

- In an inclusion classroom, general education teachers and special education teachers work together to meet the needs of students. 
- This type of classroom gives special education students the support they need and allows them to stay in the least restrictive environment.

- All students can benefit from the additional resources and supporting techniques used in an inclusion classroom.

Social relationships are an important aspect of learning processes; the training of students with and without disabilities to achieve social skills can improve the achievement of professional and social goals and reduce problems related to Behavior (David and Hamburg, 2013). Create of a positive inclusive climate, role-playing and collaborative learning can help students to be accepted in inclusive classrooms (Hamburg and Bucksch, 2015).

"Connected learning is socially embedded, interest-driven, and oriented toward expanding educational, economic, or political opportunity. It is realized when a young person is able to pursue a personal interest or passion with the support of friends and caring adults and is in turn able to link this learning and interest to academic achievement, career success, or civic engagement. Unlike efforts at educational change that focus on technology deployment or institutional reform, connected learning takes a networked approach to social change that aligns with our ecological perspective." - Mizuko Ito, professor in residence, University of California. Inclusive education approach implementation needs and challenges to tailor the teaching strategies or the means of instructional delivery in the inclusive classrooms, to address the diverse learning needs of all learners in an equitable manner.

"Acknowledging the capabilities or 'differential abilities' of all learners, the education of children with special needs in inclusive schools becomes more of a shared responsibility between the different stakeholders involved (Ahmad, 2015) and collaboration of educators, students, families and other communities' actors.

"Without a broader vision of social change, new technologies will only serve to reinforce existing institutional goals and forms of social inequity. Many prior attempts to mobilize technology in the service of educational reform have failed because interventions have focused narrowly on the deployment of particular media or technologies, without considering broader social, political, or economic conditions. (Dykes et al, 2013)

Facer (2009) underlines that innovation in technology represents both challenges as well as opportunities for inclusive education; digital innovation helps to prepare learners of all ages, particularly with special needs (with disabilities, with immigrant background, from poor families) with the skills that enable them to integrate into education. It is necessary to consider how digital innovations change traditional models of learning and the balance between the development of skills and accumulation of knowledge. By using digital technologies individuals have opportunities to access information and manage their own learning, to communicate with peers and mentors, and to innovate, create and share new materials.

Digital innovations play an important role in creating efficient, accessible and adaptable learning environments particularly in inclusive classrooms but most existing hardware and software do not take into consideration different competences/capabilities particularly of people with special needs.

Providing digital technologies particularly assistive ones, for students with disabilities involves removing

- barriers i.e. physical barriers, 
- content and materials which are not accessible,

- cognitive barriers for some learners with intellectual disabilities or specific learning problems,

- content barriers that may occur when the operating language of a device or software is not the same as a learner's mother tongue,

- didactical barriers where learning is inflexible, and teachers lack the skills to facilitate inclusive education,

- financial barriers relating to the costs of devices and software.

Assistive technology includes assistive, adaptive, and rehabilitative devices for individuals with disabilities and includes 'virtually anything that might be used to compensate for lack of certain abilities' (Reed and Bowser, 2005). Examples of assistive technologies are i.e. low-tech devices like crutches or a special grip for a pen or advanced items like hearing aids and glasses computers with specialized software for helping dyslexics to read (WHO, 2009).

Other assistive technologies are touch control devices, alternative keyboards and mouse, speech-to-text word recognition tools, word prediction programs, word processors, grammar checkers, scanners, compact disc recording (CD-R and CD-RW) drives and spell checkers (Petty, 2012).

Approaches in the use of assistive technology in inclusive education focus on using technology to train or rehearse, and to assist and enable learning. A large population of 'at risk' students are seen to need assistance, but since they often do not easily fit into a diagnostic profile, they often lack assistance (Ahmad, 2015). Assistive technology serves in bridging this gap by 'assisting' in the practice of educating children in the same classroom, including children with physical, mental and developmental disabilities (Smith et al., 2005); helping them to learn the material in a way that they can understand, by eliminating barriers that had been preventing them from being at the same level as their peers.

The use of digital technologies in inclusive education requires many sectors of expertise and activities (European Agency, 2014) like stakeholders' input and views, training of education professionals and of ICT developers.

Some principles to be taken into consideration in digital technology for inclusive education are:

- an active involvement of learners with disabilities, their families/representatives in the development

- implementation and evaluation of services which facilitates learners' access to digital technologies

- the provision of in education of people with disabilities to be aligned with the goals of inclusive education and should be available for formal, informal, blended, social and other forms of learning.

- the implementation of digital technologies in inclusive education should take a systemic approach.

It is important to measure the success of the use of digital technology in inclusive education i.e. by its actual usage, ease in accessibility by its users and in their satisfaction in interaction with their environment. Some criteria are listed below (Ahmad, 2014)

- Suitability to Users and their Environment - The devices should be compatible with the users' aspirations, emotional needs, and ways of life, and with their culture and local customs; unobtrusive by local standards, and physically comfortable from users' perspectives. 
- Inexpensive and Easy to Purchase - The devices should be low in purchase price. Government and/or NGOs can also support in the provision and purchase of the devices, free of charge or at subsidized rates. The devices should be easy and affordable to assemble or produce and maintain, so that keeping the devices in working order would require minimal resources and can be repaired with the use of locally available materials and technical skills.

- Easy-to-Use - The devices should be easily understandable by users with limited exposure to technology, portable (easy to move from one place to another), and easy to operate without prolonged training or complex skills. Depending upon the differential abilities of the learners, and the context and feasibility of the approach, assistive provisions in education can help assist students with disabilities in learning, and a collaborative effort in the use of assistive devices, assistive technology, resource room support and innovative educational strategies to promote and sustain inclusion can support these students to learn at par with their non-disabled peers in inclusive educational settings (Ahmad, 2014).

\section{DIGITAL LEARNING PLATFORMS IN INCLUSIVE EDUCATION AND TRAINING}

Technology has great potential in providing access for all learners and the process of innovation in education should use digital platforms and forums that support open communication and collaboration. Community and networked technologies change how people access information, work and participate physically or digitally in the community.

10 years ago, digital technologies in education and training focused on creating, sharing, and accessing instructional content in digital forms, including online courses, digital libraries, games, and apps. Digitizing educational content, bringing devices to school and training organizations, and one-off stand-alone learning apps were basic steps in the drive toward bringing technology into classrooms (https://www.linkedin.com/company/future-digital).

In the education and training sector, current learning platforms are complex and lead to confusion on both the student and teacher's part.

Accessible e-training modules on digital platforms as web-based courses can be taken and adapted successfully by learners with disabilities. Accessible e-Learning creates an online learning experience that includes as many people as possible regardless of their limitations whether physical, sensory, or cognitive. The challenge of developing accessible content is to develop e-Learning for a corporation, academic or training institution, or government agency and following best practices.

Research has been conducted recently that aims at adapting information systems to end users with disabilities. As part of the EU4ALL framework (https://cordis.europa.eu/project/rcn/80191 en.html) it involves the design of an integrated system that displays the most appropriate output to the user.

Referring the Web, the W3C (W3C Web Accessibility Initiative, 2013) carried out a key solution promoting people with disabilities in accessing, using and interacting with the web through the Web Accessibility Initiative (WAI). The WAI develops strategies, guidelines, and resources to make the web accessible to people with disabilities. The WAI targets, among others, web content through Web Content Accessibility Guidelines (WCAG) authoring tools through Authoring Tools Accessibility Guidelines (ATAG) and user agent through User Agent Accessibility Guidelines. In the WAI model, the WCAG is complemented by accessibility guidelines for browsing and access technologies (UAAG) and for tools to support creation of 
Web content (ATAG). Accessibility problems are not only with digital teaching platforms. Training by using digital platforms needs to address accessibility and inclusion from both the perspective of technology and pedagogy. This is particularly true for students with disabilities. Accessible content is effectively used by people in the following disability groups: blind or visually-impaired, deaf, mobility impairments and learning with disabilities students. Good accessible design makes e-Learning more accessible for everyone; poor design make content hard to access for all students with disabilities. There are a number of areas in which eLearning can work to the advantage of students with disabilities in education context. These refferb accessibility, flexibility, and disclosure. Online information can be made available in a variety of formats to best suit the person accessing it, whether this is visual through a screen displaying images or text, audio as spoken words and sound, or touch devices. For specific information on accessibility features and more about a usable and accessible platforms see examples Blackboard, Microsoft Lync, Second Life.

According to the Americans with Disabilities Act - ADA, online courses should be made accessible to students with disabilities but ADA has not provided any specific accommodation standards; each school/training organization will decide to what extent it will serve its students with disabilities. Most available e-learning systems for learners with disabilities are limited to deliver accessible learning contents. Learners with disabilities need the whole accessible platform environment and not only the accessible content because providing accessible content in a non-accessible learning environment leads to a non-accessible learning experience. In the following, we present limits of the available systems.

For example, courses should be design in navigating with keyboards, include in alt text, images and text on screen for clarity, create highly-usable course navigation, considerations when including audio and video in courses and ensure screencasts are totally accessible.

Online courses should be designed to be accessible from the beginning; implementing universal design principles at the outset avoided costs caused by the need to engage in a digital retrofit, also, design learning platform includes multiple learning modalities could very well be superior to in-person education for students with disabilities (https://www.ruhglobal.com/wpcontent/uploads/2017/01/Nabil-Eid-from-Syria-Middle-East-ICT-acces).

Accessibility of digital platforms could decrease the digital divide and support digital inclusion helping students with disabilities who use computers in different ways when taking part in training or need alternative teaching methods. Many online courses are not designed with accessibility in mind so students with a disability may be disadvantaged and it requires a process of design-redesign to accommodate the students with additional costs.

\section{EXAMPLES}

The Erasmus + project IdICT - http://www.id-ict.eu/ had as main objective to increase the competences of persons with intellectual disabilities (IDPs,) and the professionals that work with them for exploiting digital technologies with a quality of life approach and integrating them in inclusive training.

Specific objectives of the project:

- to motivate IDPs and professionals to use digital technologies (i.e. apps) for improving their quality of life and helping them to integrate into education

- to develop a training methodology, focused in the transference to accessible and usable guidelines addressed to IDPs and professionals working with them about the appropriated use of digital technologies 
- to develop an accessible and usable digital training platform, supporting the training methodology linking to selected digital tools i.e. apps.

The digital training platform is based on Universal Design criteria including awareness, training contents and tailored and adapted training materials for the proper use of the selected e-solutions based on improving the quality of life of IDP. Trainees and trainers will directly access to the training materials, guidelines and linked selected digital tools. Interactive training sessions have been organised for IDPs, professionals.

The next screenshot shows such session (Figure 1).

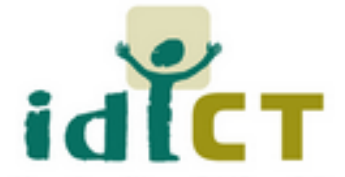

Training program for improving the Quality of Life of Persons with Intellectual Disabilities

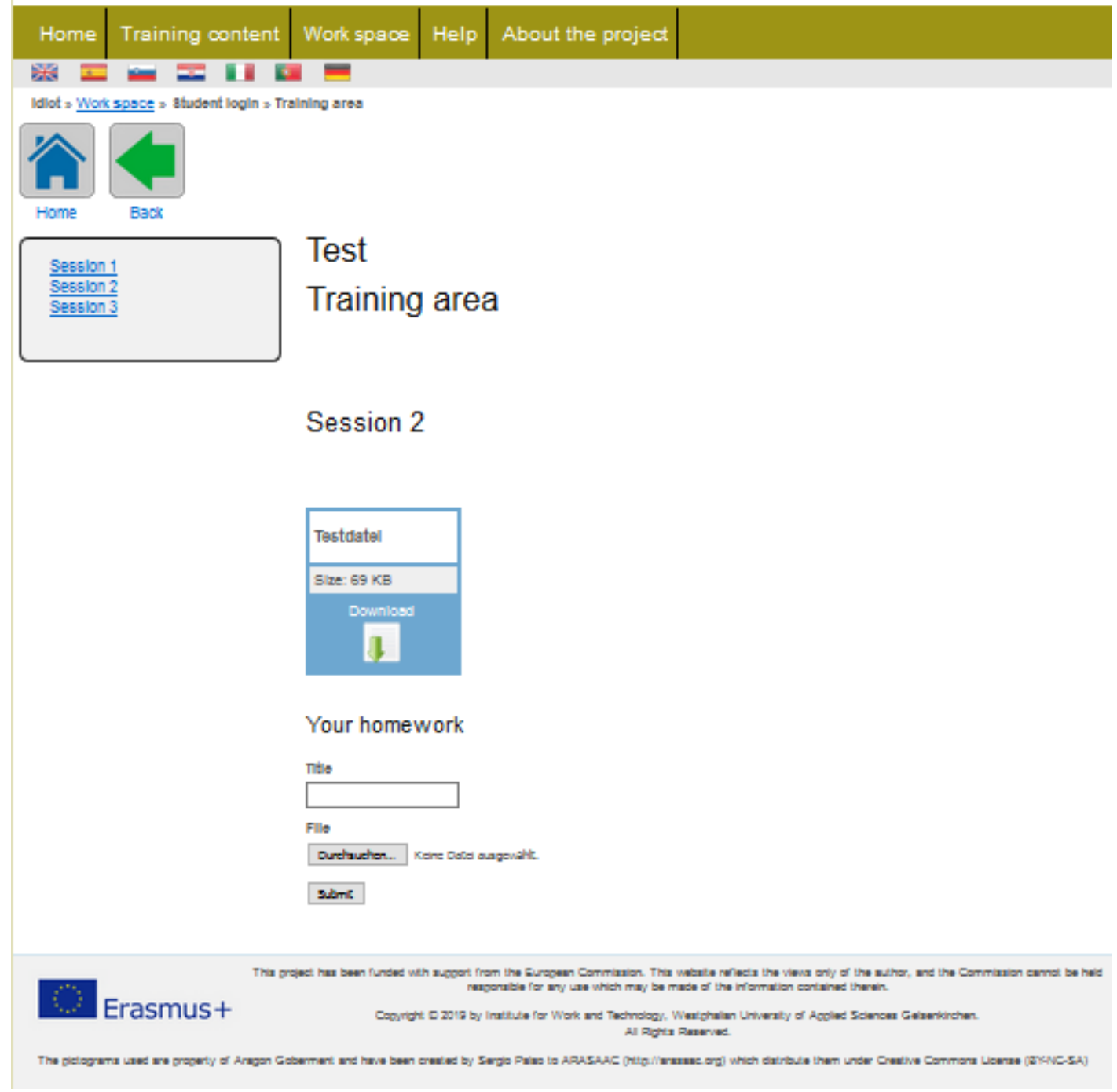

Figure 1: idICT training session

The project partners included European entities working in the field of supporting persons with Intellectual Disabilities involving a big collective of persons, families and professionals, Education experts and Technological Centres with experience in the development of digital solutions for people with special needs. 
The Erasmus+ project CP-WELLBEING http://www.cpwell.eu/ was launched with the main objective of increasing the competences (attitudes, skills, knowledge) of Persons with Cerebral Palsy - CP- teachers and professionals through an innovative training program supported by a digital training platform.

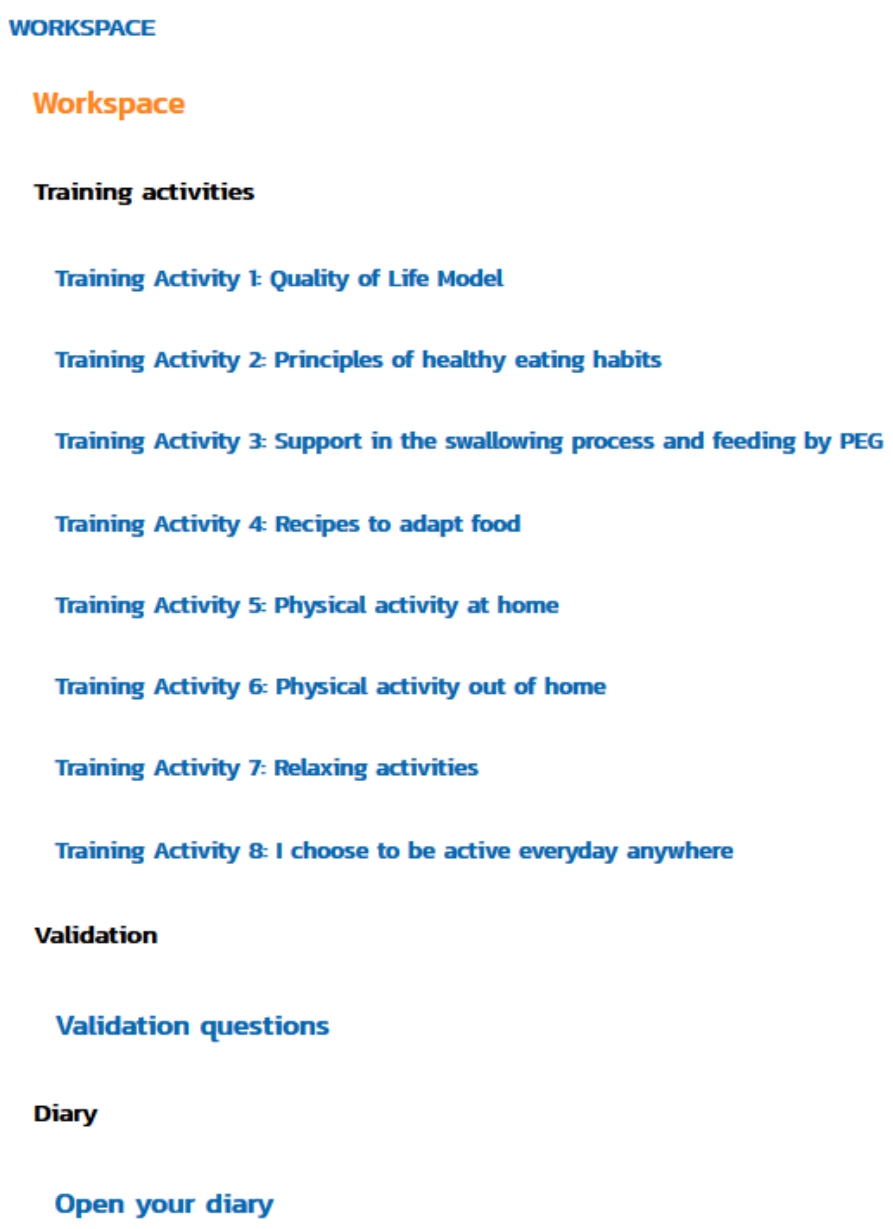

Figure 2: CPWELLBEING - Workspace overview

The project partners are CP- Organisations, education and research institutions from five European countries.

A guide has been co-created with the direct participation of end users, with the main objective of determining the key contents, methodologies and digital tools to be developed.

Some activities are:

- Development of training materials addressed to persons with CP, teachers to facilitate the implementation of inclusive activities to be used in experiential training.

- Development of an online digital training platform, promoting awareness, training content, tailored and adapted Game solutions to support the training.

- Creation of four training units in all the CP-Associations of the Consortium in order to support the integration of person with CP into education.

The Teaching Guide developed within the project to realize online and face-to face inclusive training with people with CP, professionals and volunteers in five languages is a document for professionals that will guide the teaching/learning sessions as well as the form in which the concepts will be explained to the people with CP involved in the Project. 
Through the project both the content of the training and the expected results are focused on pillars, i.e. inclusive physical activity and finally the influence of both on the quality of life of the person, which we focus on the dimensions of quality of life.

This piloting was carried out in all the participating countries of the project, using all of them, the same satisfaction questionnaire. This satisfaction questionnaire was carried out using a Likert scale where one was in disagreement and five totally agreed. It gathered their satisfaction with regard to their expectations, the knowledge and skills acquired, their training needs, the contents of the workshop, the trainer, the work as a team and the dynamics throughout the formative activity, the space, the time, the space for personal reflection and the general assessment.

All this material can be consulted on the website https://www.cpwell.eu/ where the teaching guide, the presentations and the execution guide of each of the training activities are available to the public. The teaching guide details the activities that can be found in the private spaces of the participants of the supporting ICT platform.

The CP-Wellbeing platform support the 8 e-training activities i.e. for Training Activity 1 some issues: (https://www.cpwell.eu/en/workspace/training-activity-1-quality-of-life-model/)

- Referring Content: A welcome text, Slideshow presentation of training activity 1, Execution guide of training activity 1 as PDF (only seen by the trainer), Explanation text for the homework, Link to homework of training activity 1, Questionnaire, Healthy habits annex as PDF file

- The platform supports the participants at Homework

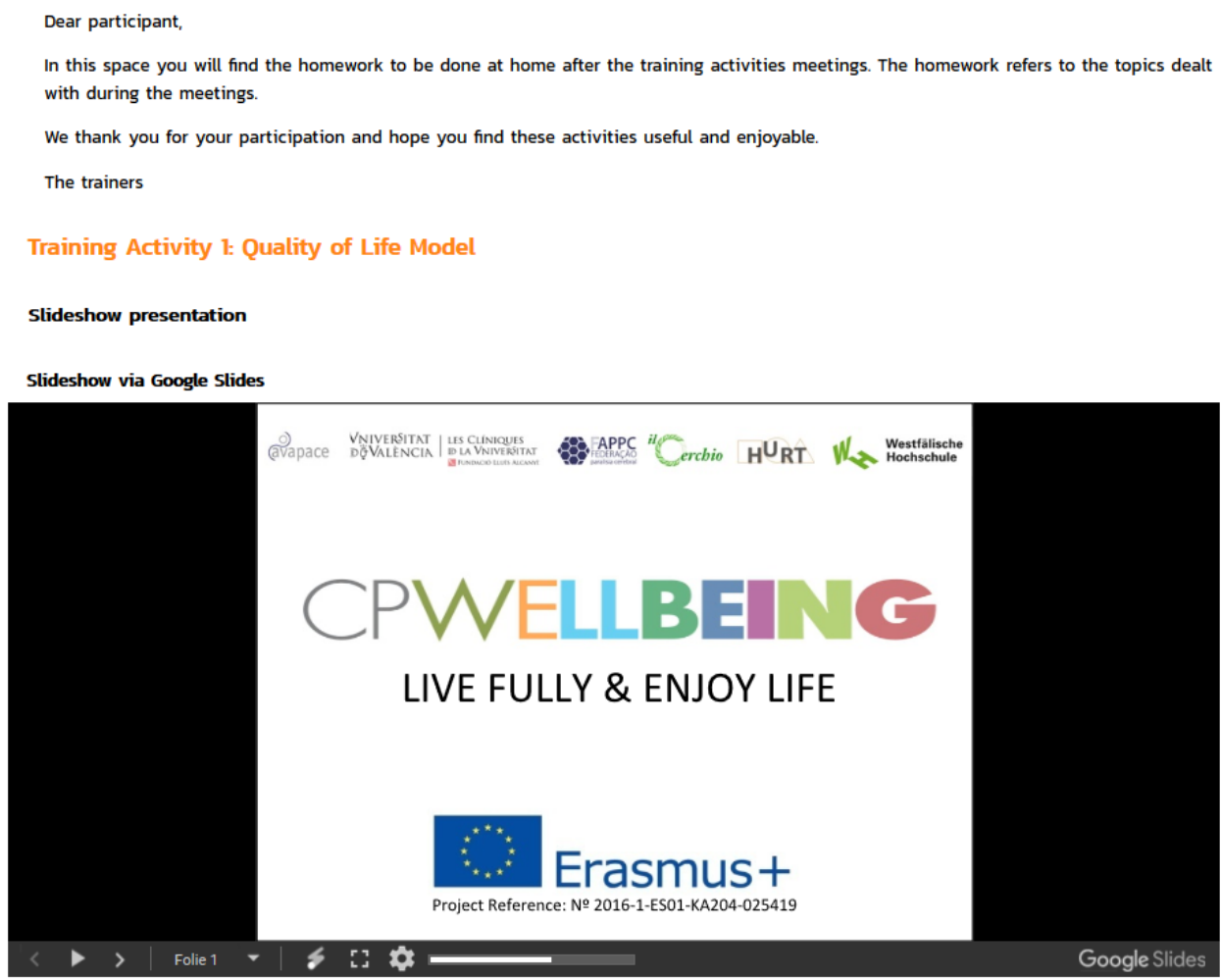

Figure 3: CPWELLBEING - Training Activity 1: Quality of Life Model, Slideshow 


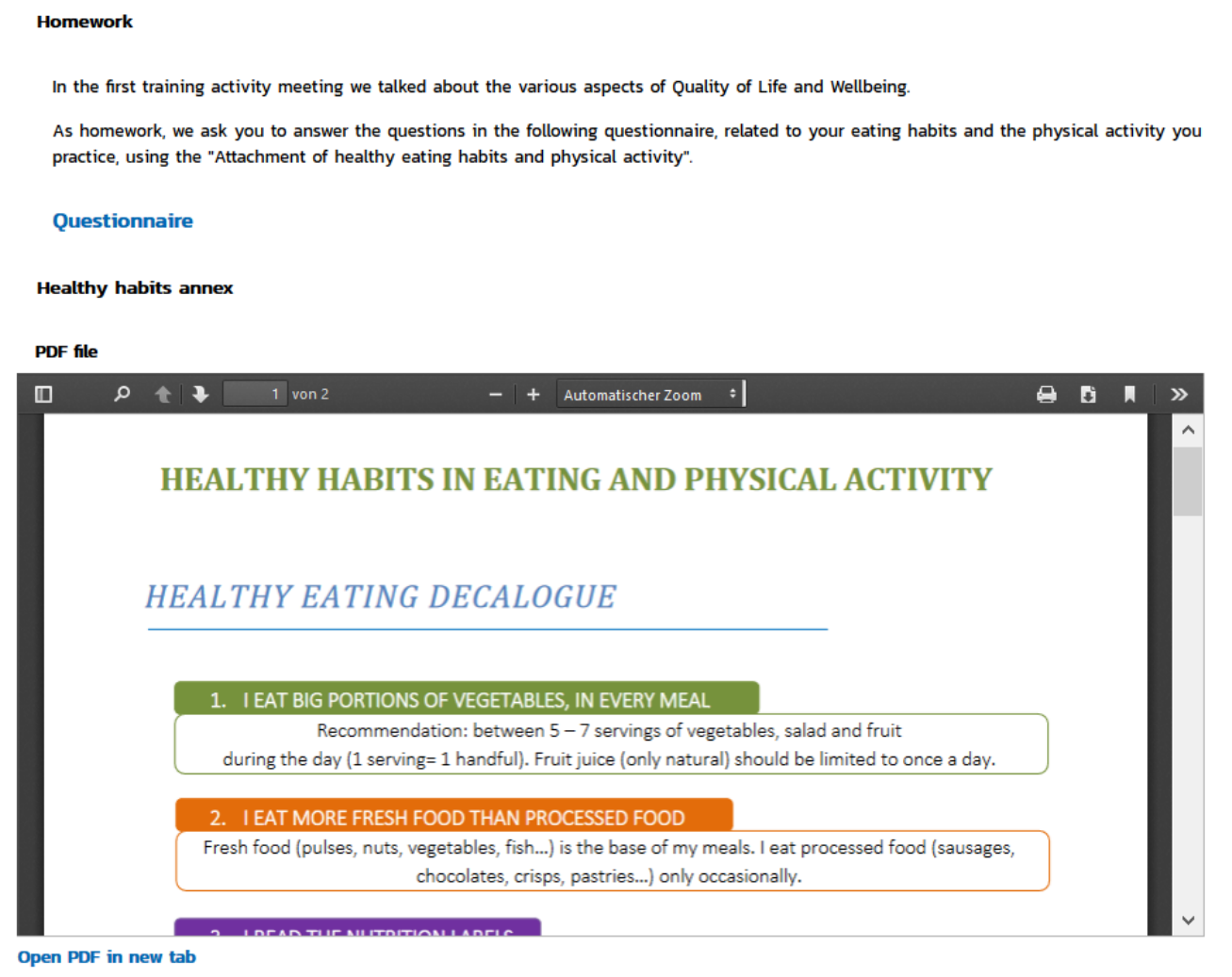

Back to the workspace

Figure 4: CPWELLBEING - Training Activity 1: Quality of Life Model, Link to homework and annex

1. What are the habits of your daily life that you follow to take care of your health? Annex of healthy habits in eating and physical activity. $\mathrm{m}$
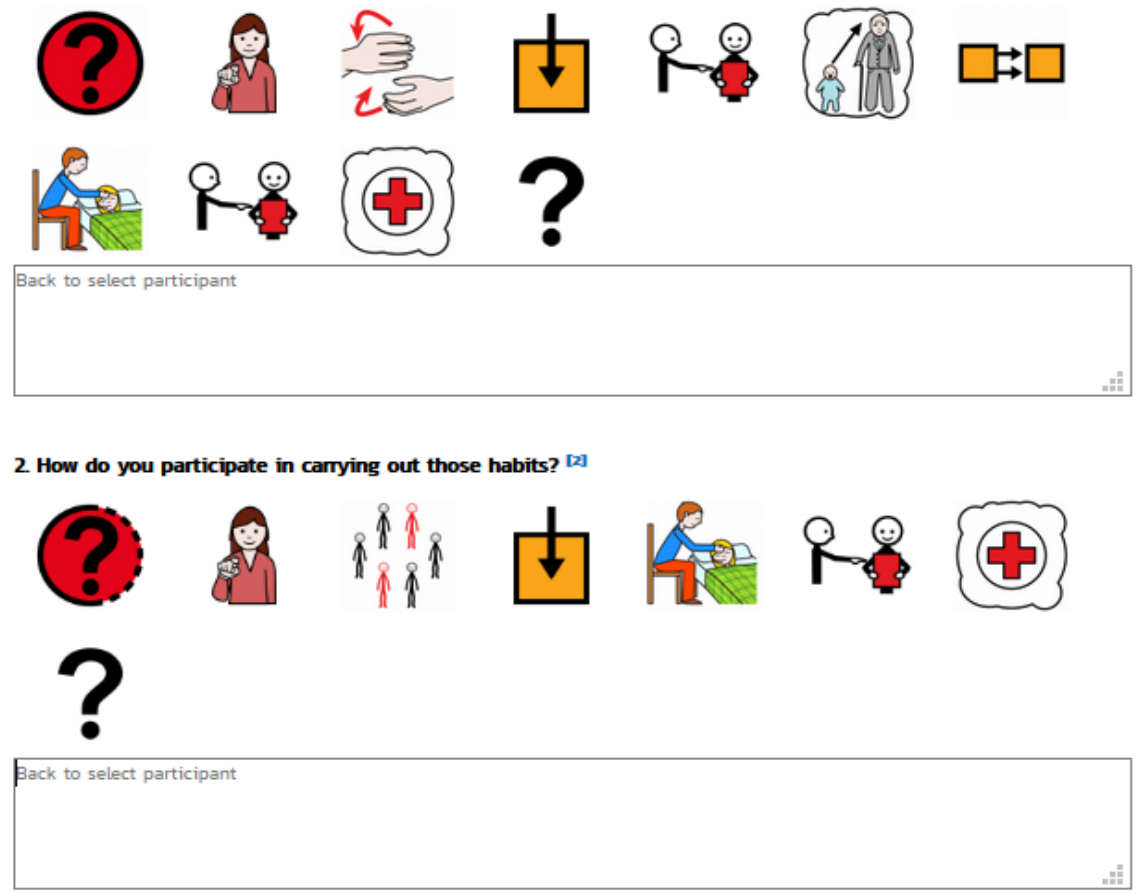

3. List the support products and / or human supports that you use to carry out those habits. ${ }^{[3]}$

Figure 5: CPWELLBEING - Training Activity 1: Quality of Life Model, Beginning of the questionaire as homework 


\section{CONCLUSION AND FURTHER WORK}

Digital divide and digital inclusion, these issues have remained largely unaddressed by both the public and the governments in many countries.

People with disabilities experience a significant digital divide in all countries. Digital divide referring persons with disabilities is aggravated by the relatively slow development of accessible assistive technologies, digital platforms and e-training. In addition, current strategies aimed at improving digital inclusion particularly referring inclusive education/training facilities and internet participation of this population are not fully effective on both a national level and European one. With the futures of many at risk students including people with disabilities, migrants, refugees, it is critical for society to gain a deeper understanding of the impact the digital divide and digital inclusion have on inclusive education and formulate ways to combat digital inequity.

\section{References}

F. Khursheed Ahmad (2014)."Assistive Provisions for the Education of Students with Learning Disabilities in Delhi Schools." International Journal of Fundamental and Applied Research, vol.2, no 9. pp.9-16.

F. Khursheed Ahmad (2015). "Challenging Exclusion: Issues and Concerns in Inclusive Education in India." Researchpaedia, vol.2, no.1, pp.15-32.

F. Ballestero (2002). La brecha digital. El riesgo de la exclusión en la sociedad de la información, Madrid, Fundación Retevisión.

Becta (2007). Inclusive learning: an essential guide. Retrieved from http://beeit.co.uk/Guidance\%20Docs/Becta\%20Files/Publications/29.\%20Inclusive\%20learning\%20An\%20essential\%20 guide.pdf

Broadband Commission for Digital Development, G3ict, IDA, ITU, Microsoft, The Disability, 2013

A. David, I. Hamburg (2013). Integrating vulnerable and marginalized groups into vocational education and training through innovative solutions.In Problems of education in the 21st century, 56, pp. 42-58.

V. Donelly, A. Watkins (2011). Teacher education for inclusion in Europe. Prospects, 41, 3, pp. 341-53

E. Dykes, J. Groff, H. Renfrew-Knight, D. Sutch (2013). Driving social innovation in education. Retrieved from http://www.jengroff.net/pubs_files/Social_Innovation_in_Education 2013

Eurydice (2011). Key Data on Learning and Innovation through ict at School in Europe 2011 [online] http://eacea.ec.europa.eu/education/eurydice/documents/key_data_series/129EN.pdf.

European Agency (2014). Model policy for inclusive ICTs in education for persons with disabilities. Retrieved from https://www.european-agency.org/sites/default/files/UNESCO-

G3ict\%20Model\%20Policy\%20on\%20Inclusive\%20ICTs\%20for\%20Education\%204-2014.pdf

K. Facer (2009). Educational, Social and Technological Futures: A Report from the Beyond Current Horizons Programme. In Futurelab: Bristol, United Kingdom.

I. Hamburg, S. Bucksch (2015). ICT-based approaches to support learners with disabilities. In Journal of educational policy and entrepreneurial research (JEPER) 2, no. 6, pp. 1-12

http://jeper.org/index.php/JEPER/article/view/132

I. Hamburg, G. Lütgen (2018). Digital platforms to support feeding, physical activity and training by cerebral palsy. In Archives of business research 6, No. 3, pp. 120-128.

ICF (2001):"International Classification of Functioning, Disability and Health". World Health Organization, ISBN13: $9789241545440,228 \mathrm{pp}$.

IstenicStarcic, A. (2009). Educational technology syllabus. In UP PEF higher education, pp. 12-15 Koperhttp://jeper.org/index.php/JEPER/article/view/132

E. O'Gorman (2005). Setting Standards for Teacher Education in Special Educational Needs in Ireland.In 30th Annual Conference ATEE. Amsterdam, October 2005, pp. 377-381

Partnership on Measuring ict for Development (2010), "Indicadores clave sobre tic" [online] http://www.itu.int/dms pub/itu-d/opb/ind/D-IND-ict CORE-2010-PDF-S.pdf. 
Red ticBolivia [online] http://www.ticbolivia.net/.

D. W. Omole (2013). Harnessing information and communication technologies (ICTs) to address urban poverty: Emerging open policy lessons for the open knowledge economy. Information Technology for Development 19(1), pp. 86-96.

R. E. Petty (2012). Technology Access in the Workplace and Higher Education for Persons with Visual Impairments: An Examination of Barriers and Discussion of Solutions. Independent Living Research Utilization at TIRR: Houston, Texas.

L. Porter, D. Smith (Eds.) (2011). Exploring inclusive educational practices through professional inquiry. Boston, MA: Sense Publishers

P. Reed, G. Bowser (2005):"Assistive technologies and the IEP" in Edyburn, D., Higgins, K., Boone, R. (Eds.) Handbook of Special Education Technology Research and Practice. Knowledge by Design Inc. Whitefish bay.

S. S. Robinson (2005). "Reflexiones sobre la inclusión digital", Nueva Sociedad, No. 195 [online] http://www.nuso.org/upload/articulos/3244 1.pdf.

D. Samant, R. Matter, M. Harniss (2013). Realizing the potential of accessible ICTs in developing countries. Disability and Rehabilitation: Assistive Technology 8(1), pp. 11-20.

R. J. Simeonsson, M. Leonard, D. Dollar, E. Bjorck-Akessoon, J. Hollenweger, nd A. Martinuzzi (2003):"Applying the international classification of functioning, disability and health (ICF) to measure childhood disability. Disability and Rehabilitation vol.25 (11-12), 11-17.

R. W. Smith, D. R. Austin, D. W. Kennedy, Y. Lee and P. Hutchinson (2005): Inclusive and special recreation: Opportunities for persons with disabilities (5th Ed.). Boston: McGraw Hill.

UNESCO (1994): The UNESCO Salamanca Statement and Framework for Action on Special Needs Education. UNESCO, Paris.

UNESCO (2008). Inclusive education in Germany. Retrieved from https://www.unesco.de/en/bildung/inklusivebildung/inklusive-bildung-deutschland.html

WHO (2009):"Assistive devices/technologies", Available at: http://www.who.int/ disabilities/technology/in/

User Agent Accessibility Guidelines 1.0. (2013). http://www.w3.org/ TR/WAI-USERAGENT/ (July 2013).

M. Vincente, A. J. Lopez 2011. Assessing the regional digital divide across the European Union-27, Telecommunications Policy, Vol. 35, No. 3, pp. 220-237.

W3C Web Accessibility Initiative (2013). http://www.w3.org/WAI/gettingstarted/Overview.html

Web Content Accessibility Guidelines, 2013. http://www.w3.org/TR/ WCAG10/

WHO (World Health Organization) and World Bank (2011). World Report on Disability.

World Bank. (2008). Social inclusion through ICT for Tunisian disabled.

http://web.worldbank.org/archive/website01055/WEB/0 CO-93.HTM 